\title{
Adoption of the Wealth Index Approach in Analyzing the Determinants of Household's Poverty in Tanzania
}

\author{
Yoeni S. Kaniki* \\ Department of Business and Entrepreneurship Studies (BES) \\ National Institute of Transport (NIT), P.O.Box 705 Dar es Salaam \\ Cornelio Swai \\ Department of Business and Entrepreneurship Studies (BES) \\ National Institute of Transport (NIT), P.O.Box 705 Dar es Salaam \\ Daudi Kitomo \\ Department of Business and Entrepreneurship Studies (BES) \\ National Institute of Transport (NIT), P.O.Box 705 Dar es Salaam \\ Arnold Binagwa \\ Department of Business and Entrepreneurship Studies (BES) \\ National Institute of Transport (NIT), P.O.Box 705 Dar es Salaam
}

\begin{abstract}
This study examines the determinants of poverty in Tanzania using the 2015 Tanzania Demographic and Health Survey data. Ordered logit model was used to model the determinants of poverty and the study revealed that age, sex, household size, level of education, marital status, type of residence and access to financial services are significant in explaining the status of poverty. All of the mentioned variables are significant at $1 \%$ except sex of the household head which was significant at 5\%. Since it is the global goal to reduce poverty, the study recommends that the government should invest more in education to improve knowledge and skills of individuals, improve financial services and financial inclusion especially in rural areas to eradicate poverty and remove rural-urban disparity.
\end{abstract}

Keywords: Poverty, Household, Wealth Index, Ordered logit model and Tanzania

DOI: $10.7176 / \mathrm{JESD} / 12-14-03$

Publication date:July $31^{\text {st }} 2021$

\subsection{Introduction}

Poverty has been amongst the most sensitive global issues of discussion for many years because of the negative impact it has on the community and environment. World Bank has set goals to reduce extreme poverty and shared prosperity but these goals have been successfully achieved in some regions (for example Europe and Central Asia) while not in other regions specifically in Sub-Saharan Africa, the region to which Tanzania is a part of. Poverty can be defined as a condition of not only having insufficient quantities of basic necessities, but as the lack of, or the violation of, the right to these basic necessities such as food, health, education and the like (Sengupta, 2003).On the other hand, (Narayan, 2000) defines poverty as the situation whereby people lack material well-being, insecurity, social isolation, suffer from psychological distress, lack of freedom of choice and action, unpredictability, lack of long-term planning horizons, low self-confidence and not believing in one self. Poverty is widely discussed because the process of economic development in any country involves reduction of poverty, improvement in the health care and education attainment. These have been mentioned as one among the United Nations Millennium Development Goals (MDGs) (Todaro \& Smith, 2015).

Many countries around the world are struggling every day to end extreme poverty. According to (World Bank, 2018) the share of the global population suffering from extreme poverty as measured by the International Poverty line (IPL) USD 1.90 as of 2011Purchasing Power Parity (PPP) fell by 24.7 percent from 35.9 percent in 2011 to 11.2 percent in 2013. Further, some recent global estimates show that there was an increase in the rate of poverty reduction as from 2013 to 2015 about 68 million people were lifted out of extreme poverty. However, the majority of global poor reside in Sub-Saharan Africa (SSA) as out of the world's 28 poorest countries with higher rates of extreme poverty, 27 countries are located in SSA with 30 percent level of extreme poverty (World Bank, 2018). Majority of poor people living in rural areas suffer from under nutrition and poor health, have little or no literacy, live in environmentally degraded area, have little political voice, are socially excluded, attempt to earn a meager living on small and marginal farms or in depilated urban slums (Todaro \& Smith, 2015).

Many countries have tried to comply with the 2030 Agenda for Sustainable Development to ensure that they are not left behind by reducing the level of extreme poverty. The agenda is geared to reduce extreme poverty worldwide to less than 3 percent but so far only two regions namely Europe and Central Asia with only 7 million 
people who are poor have managed to attain this goal.

Castañeda et al., (2016) argue that in many parts of the world the rate of economically dependent members per working-age adult is high because the poor in many part of the world live in larger households. However, this rate has been declining in many regions of the world unlike in SSA where the fast rate of population growth causes the increase in total poor population and hence leads to increased dependency ratio. This is because the growth is less effective to reach the poor population residing in different areas of the region. Also, Adeyemi, Ijaiya, \& Raheem (2009) argue that the reasons for poverty in SSA include the increased rate of population growth, inflation, external debt servicing, lack of safe water, low economic activities, gender discrimination, ethnic and religious conflict and HIV/AIDS. The World Bank Report adds that the speed of extreme poverty reduction in SSA is slowing down because of slower than average economic growth, concentration in capitalintensive sector, higher than average population growth, low levels of human capital and access to basic infrastructure and finally increased levels of fragility and conflict. Also, the current COVID-19 pandemic has slowed down the rate of poverty reduction as over 20 years extreme poverty was declining steadily but recently due to pandemic the number of people living in poverty has increased by about 120 million and is expected to further rise to 150 million by the end of 2021 (World Bank, 2021)

Since independence, Tanzania's development process has centered on human development by focusing on the major development problems such as ignorance, diseases and poverty (URT, 2000). This focus however is made possible through a strong economy which the government is trying to build by using various strategies to ensure that the country attains a middle-income target and eradicate the existing level of extreme poverty by 2025. However, there is mismatch of pace between economic growth and poverty reduction because poverty continues to decline at a low pace compared to the rate of economic growth. This emerges from the fact that the sectors which have high contribution to Gross Domestic Product (GDP) have low contribution to poverty reduction and vice versa. For instance, mining, communication and transport sectors have high contribution to GDP but less to employment which have high implication on poverty reduction as compared to agriculture sector which contributes an average of 30 percent to GDP but higher to poverty reduction because of employing many people, more than 66.3 percent.

The effort of fighting poverty is evidenced by the trend of reduction of multidimensional as well as extreme poverty which were reduced from 64 percent and 31.3 percent in 2010 to 47.4 percent and 17.7 percent respectively in 2015 (URT, 2018). This was successful because the government used policies and strategies which increased access to electricity and rates of ownership of assets which include mobile phones, radios and motorcycles. Availability of electricity in many areas, possession of mobile phones and motorcycles have accelerated the pace of poverty reduction by the means of self-employment to many poor through establishment of various new investments which require only small amount of capital, conducting online business through mobile phones but also to transport passengers and goods using motorcycles (Bodaboda), improvement in social services provision such as education, health and water services. The reduction of multidimensional poverty go in line with target of the National Five Year Development Plan (FYDP II) which is geared to the reduce Multidimensional Poverty Index (MPI) to 38.4 percent by $2020 / 21$ and ultimately to 29.2 percent by $2025 / 2026$ (URT, 2018).

The World Bank announced that Tanzania had been upgraded from low to low middle income status from July 1, 2020 which was planned to be reached on 2025. This tremendous achievement is due to the acute effort done by the Government of Tanzania by build a strong economic performance of over $6 \%$ real gross domestic product (GDP) growth on average for the past decade. Tanzania's GNI per capita increased from \$1,020 in 2018 to $\$ 1,080$ in 2019, which exceeds the 2019 threshold of $\$ 1,036$ for lower-middle income status. However, discipline in financial expenditure, prevailing peace and tranquility are also helped the country to earn the middle income status.

This paper aims at analyzing the determinants of poverty in Tanzania using a Demographic and Health Survey Data and Wealth Index Approach. This is due to the fact that analysis of the determinants of poverty by many researchers has mostly focused attention on household income, expenditure and consumption which rely mostly on economic factors and single dimension measures. According to Gachanja \& Kinyanjui (2016), these measurement variables are inherently inaccurate in analyzing the status of poverty in developing countries unlike in developed countries. Hence, the analysis based on household income, expenditure and consumption fails to capture all aspects necessary in determining the poverty level of the households.

\subsection{Review of Literature}

The empirical literatures on the determinants of poverty have been well established in the country as well as around the world. Adeyemi et al., (2009) examined the determinants of poverty in Sub-Saharan Africa using multiple regression analysis technique for 48 countries. The results of the study showed that many SSA countries have low level of development or high poverty rate because of the increase in the rate of population, inflation and external debt servicing, lack of safe water, low economic activities, gender discrimination, ethnic and 
religious conflicts and prevalence of HIV/AIDS. A study by Kabuya,(2007) points out other causes of poverty in Africa, which include income inequality, conflicts, location, natural disasters, ill health and disability, inheritance of poverty, education and skills, as well as gender discrimination. Gender discrimination goes in line with the results of DFID, (2005) which argues that social exclusion of people causes poverty due to the fact that people do not participate equally in social activities. Other researchers add that poverty can be caused by lack of income and productive resources sufficient to ensure sustainable livelihood, hunger and malnutrition, ill health, limited or lack of access to education and other basic services, increased morbidity and mortality from illness, homelessness, inadequate, unsafe and degraded environment, social discrimination and exclusion but also lack of participation in decision making (WB, 1990; UN, 1995 and WB, 2001). Other factors identified to cause poverty include inadequate access to employment opportunities, physical assets such as land, capital and credit, means of supporting development, markets and assistance for people living in marginal areas and victimized by transition poverty and lack of participation (Obadan, 1997). Furthermore, Korf et al. (2005) found that poverty is linked to lack of resource endowments such as oxen, land, and human capital.

Narayan et.al. (2000a) explain that poverty is caused by two main factors which are structural causes and traditional causes. Structural causes include; limited resources, lack of skills, locational disadvantage and other factors that are inherent in the social and political set-up. Traditional causes on the other hand consist of natural calamities such as drought and man-made disasters such as wars and environmental degradation among others.

Majeed and Malik (2014) employed logistic regression technique in Pakistan to examine household characteristics and personal characteristics of the household head as the determinants of poverty. They revealed the importance education has on poverty reduction. Their study discovered that poverty is greatest among the less literate households and declines as education level increases.

Human capital accumulation plays a great role in the development process and reduction of poverty (Chikelu, 2016) through improved cognitive and non-cognitive abilities, skills and health of a labor involved in development process. Many countries are now investing in human capital development due to the role it plays in economic growth and development as reflected in poverty reduction. Human capital significantly reduces the chance of being poor (Mok, Gan, \& Sanyal, 2007). Obadan (1997) points out that low endowment of human capital, destruction of natural resources are among the causes of poverty. According to Coulombe \& Mckay (1996) low level of education significantly increase the probability of household being poor. Zuluaga, (2002) adds that education improves decisions and behavior regarding housing and can avail credit facility in a better way thus allowing people to escape and avoid poverty. Household heads play an important role in poverty reduction depending on the way they manage their households. This is also influenced by the level of education of the head of the household. When heads of households attain higher education, in other words, when there is an increase in the schooling of the household heads make the level of poverty to be much lower as there is positive impact between increase in schooling and productivity and earnings which is a significant factor in poverty reduction (Tilak, 2002; Abuka, Atingi-Ego, Opolot, \& Okello, 2007 and Al-samarrai, 2007).

Okojie (2002) and Bundervoet (2006) analyze the importance of the head of the household on poverty reduction. The reason behind is to know among the households headed by male or female, which ones suffer from poverty? The results revealed that incidence of poverty, poverty gap and poverty severity are more prominent in households headed by female as compared to male headed households. This results comply with the results of (Zuluaga, 2010) who argues that female headed households are more likely to have less income than male headed households which signifies higher rates of poverty. (Horrell \& Krishnan, 2006) conducted a study to analyze poverty and productivity in female-headed households in Zimbabwe and revealed different forms of poverty for female-headed households which in turn affect their ability to improve productivity particularly in agriculture. However, the women empowerment agenda plays important role in poverty reduction because empowerment eradicates the conditions that cause powerlessness and dependencies through engaging women in different socio-economic activities, inspiring them to participate through action plans and suggestions and encouraging them to accept responsibilities (Arif, 2014).

Shaukat, Javed, \& Imran, (2019) conducted a study in Pakistan to assess the poverty status using wealth index as substitute to household income and consumption. Using DHS data and multivariate analysis technique the study revealed that poverty status of the household is significantly associated with the size of the household, dependency ratio, sex and age of the household head. Moreover, higher education reduces the likelihood of the household being poor. On the other hand, dependency ratio increases the likelihood of poverty. Sex of the head of household indicates that male-headed households are more likely to have poverty-lower wealth index compared to female-headed households. Aikaeli (2010) in his study on the determinants of rural income in Tanzania revealed that rural income was lower in female-headed households than male-headed households. This justifies the existence of high rate of poverty in female-headed households than the counterpart. Moreover, he found the need of improving the level of education of rural households, size of household labor force, acreage of land use by households in rural areas and ownership of a non-farm rural enterprise as they are significantly and positively related to income of rural households in Tanzania. 
In Nigeria, Apata, Apata, Igbalajobi, \& Awoniyi (2010) employed probit model on a sample of 500 small farmers to examine the determinants of rural poverty. The study revealed that access to micro-credit from financial institutions, education level, participation in workshops or seminars related to agriculture, livestock asset and extension services significantly influence the probability of household's chronic poverty.

Ermiyas, Batu, \& Teka (2019) examined the determinants of rural household's poverty in Dejen - Ethiopia using primary data collected through questionnaire from 204 households selected through multi-stage sampling technique. Initially, they employed Foster, Greer and Thorbecke (FGT) poverty index to examine the extent and severity of poverty, and it was found that out of the total sampled households nearly 49 percent lives below the poverty line with an average poverty gap of 0.083 and severity gap of 0.065 . Nevertheless, the results of the determinants of rural poverty studied indicate that household size (family size), sex of the head of households, dependency ratio and ownership of livestock are key determinants of rural poverty. Specifically, poverty status is negatively correlated with the number of livestock owned by the households and sex of the head of the households. Household size and dependency ratio have shown positive relationship to poverty status of the households.

In Kenya, Gachanja \& Kinyanjui (2016) conducted a study to analyze the household poverty determinants using a demographic and health survey data and wealth index approach. Both binary and ordered logistic models used revealed that years of education of the head of the household, marital status, household size and the region of residence strongly determine the welfare status of the household and therefore, important in explaining household probability to poorest.

Mutabazi, Sieber, Maeda, \& Tscherning, (2015) analyzed determinants of poverty and vulnerability of smallholder farmers in the rural area of Morogoro Region -Tanzania. The study used 240 households selected at one point in a time in six villages of the region. Researchers employed descriptive and econometric approaches such as Three Stages Least Squares (3SLS) and Generalized Methods of Moment (GMM) for data analysis and the results revealed that in the studied six villages there was prevalence of income poverty. More specifically, income poverty was relatively low in agro-climatically favourable areas than in less favourable areas. On the other hand, majority of the households (3/4) were vulnerable and the pattern of such vulnerability tended to overlap with poverty rates in the studied six villages. Nevertheless, ageing of the household head has accelerated the level of vulnerability; large-sized households were more income poor than small-sized houses because of higher consumption expenditures as compared to the counterpart. The results also revealed that farming experience and increased farm size have enhanced the level of income and as a result reduce the probability of future vulnerability. Having higher income contributes to wealth formation through improved access to assets and housing amenities. Lastly, the study found that, farmer with perception that climate change is induced by human tended to have significantly higher income than the counterpart.

Yusuf et al., (2015) assessed the determinants of rural poverty in Mkinga District (Tanga Region) where 93 percent of the sampled respondents were poor. Moreover, gender of household, size of land owned by the households, the size of farm used in farming, household size and the dependency ratio were found to be related to the level of poverty. The study recommends that the women should be empowered to have positive attitude towards participating in various economic activities and ensure the utilization of resources around them is as optimal as possible. To achieve the goal of reducing poverty in the area, the government has to ensure it provides proper infrastructural settings.

\subsection{Data and Method \\ 3.1 Sample Design}

This study uses the 2015 Tanzania Demographic and Health Survey (TDHS) data. 2015 TDHS is the fifth survey conducted; prior surveys being 1991-92 (TDHS), 1996 (TDHS), 2004-05 (TDHS) and 2010 (TDHS). In this recent survey, 13,400 households were selected as a representative sample. The survey was mainly concerned with the women and men aged 15 - 49 years who are usual residents or slept in the households that night before the survey. The survey managed to interview 13,000 women and 3,200 men belonging to the age group mentioned above. The sampling frame for this survey was the Tanzania Population and Housing Census (2012) conducted in Tanzania in 2012. All over the country the enumeration areas (EAs) were considered as a sampling frame. The sample was selected using stratified sampling where each region was separated in urban and rural areas.

In the first stage, 608 EAs were selected (180 from urban areas and 428 from rural areas). In the second stage, from each selected cluster 22 households were selected making the total number of 13,376 households. However, due to differences of the household size among regions, adjustment was made to select 20 or 21 clusters for all regions except in Dar es Salaam (37 clusters) and 15 clusters for each region located in Zanzibar. This is due to the fact that Dar es Salaam is an urban area only and the size of the households in regions of Zanzibar is large. 


\subsection{Empirical Regression Model}

This study employs the ordered logit model due to the categorical nature of the dependent variable and the households use latent movement from the lowest category to highest category. The outcome variable is expressed as follows:

$$
y=\left\{\begin{array}{l}
\text { poorest } \\
\text { poorer } \\
\text { middle } \\
\text { richer } \\
\text { richest }
\end{array}\right.
$$

The modelling uses the latent variable which is not observable but linearly depends on the vector of explanatory variables $\left(x_{i}^{\prime}\right)$. This latent variable can be interpreted as the utility between choosing categories and is modeled as given by equation (1) below:

$$
y_{i}^{*}=x_{i}^{\prime} B+\varepsilon_{i} ; E\left(\varepsilon_{i} \mid x_{i}\right)=0
$$

Assuming that the epsilon follows the logistic cumulative distribution and since the authors are concerned with the probability of belonging in category $\mathrm{j}$, then

$$
\begin{gathered}
\operatorname{prob}\left(y_{i}=j \mid x_{i}\right)=\operatorname{prob}\left(\alpha_{j-1}<y_{i}^{*} \leq \alpha_{j}\right) \\
\operatorname{prob}\left(y_{i}=j \mid x_{i}\right)=\operatorname{prob}\left(\alpha_{j-1}<x_{i}^{\prime} B+\varepsilon_{i} \leq \alpha_{j}\right)
\end{gathered}
$$

Rearranging equation (3) results to:

$$
\operatorname{prob}\left(y_{i}=j \mid x_{i}\right)=F\left(\alpha_{j}-x_{i}^{\prime} B\right)-F\left(\alpha_{j-1}-x_{i}^{\prime} B\right)
$$

Equation (4) provides the underlying structural model for estimation by maximum likelihood estimation (MLE) using both dependent and independent variables. Moreover, the ordered logit model that is estimated in this study is expressed as equation (5) below:

$$
\begin{gathered}
\text { prob }\left(\text { Povstatus }=j \mid x_{i}\right)=F\left(\alpha_{j}-x_{i}^{\prime} B\right)-F\left(\alpha_{j-1}-x_{i}^{\prime} B\right) \\
\text { where: } x_{i}^{\prime} B=\beta_{1} \text { Age }_{i}+\beta_{2} \text { Ages }_{i}+\beta_{3} \text { Sex }_{i}+\beta_{4} \text { HHsize }_{i}+\beta_{5} \text { Education }_{i}+\beta_{6} \text { Marstat }_{i} \\
+\beta_{7} \text { Residence }_{i}+\beta_{8} \text { FSaccess }_{i}
\end{gathered}
$$

The following is the description of the variables used in regression:

\section{Dependent Variable}

This study uses poverty status (Povstatus) as a dependent variable. This variable is categorical in nature having five (5) categories such as $0=$ 'poorest', 1 = 'poorer', 2 = 'middle', 3 = 'richer' and 4 = 'richest' households. This ordering is logical since household movement from being poorest to being richest makes sense.

\section{Explanatory Variables}

The study at hand uses household size (HHsize) which is measured as the number of household members, age of the household head (age). It also uses sex of the household head (Sex) which takes the value of 1 if the household head is a male and 0 otherwise. The marital status of the household head (Marstat), which indicates the marital status of household head if he/she is $0=$ "never in union", 1 = "living together with his/her partner" and 2 = living without a partner". The level of education of the household head (education) has four categories namely 0 = 'no education', 1 = 'primary education', 2 = 'secondary education' and 3 = 'higher education'. Taking into account where the household is located, the type of place of residence (Residence) was considered. It takes 1 if the household resides in urban area and 0 otherwise. Finally, we consider the contribution of financial technology (access to financial services) as the determinant of poverty by incorporating the use of mobile phone for financial transaction (FSaccess). This is a dummy variable with values 0 if the 'household does not use phone to access financial services' and 1 if the 'household uses phone for financial services'.

\subsection{Data Analysis}

This paper uses STATA Version 16 to analyze the data using the ordered logit regression approach. This approach is suitable when the dependent variable is categorical with more than two categories thus is capable of predicting the probabilities of all possible outcomes basing on several selected independent variables (Noor Amira Mohamad, Zalila Ali, Norlida Mohd Noor, 2016). In addition, the transformation of household from being poorest to richest is logically ordered following the latent nature implying that the values assigned to each category or outcome is no longer arbitrary. The ordered logit regression model is estimated using the maximum likelihood estimation (MLE) approach assuming independence across observations and this estimation procedure is an iterative with the first iteration being the log likelihood of the 'empty' or 'null' model (i.e. a model without 
predictors). In addition, at each next iteration there is inclusion of predictor(s) and the log likelihood increases as the goal is to maximize the log likelihood (Long, 1997).

\subsection{Findings and Discussion \\ 4.1 Descriptive Statistics}

Table 1 shows the summary statistics for the variables used in the study. Since it is difficult to interpret the statistics for categorical variables especially those which are not ordinal the study will concentrate in interpreting dummy variables and the continuous variables used in the analysis. The mean age is 36 years which implies that majority of the sampled household heads are mature enough to engage in various economic activities for poverty reduction. On the other hand, the mean number of household members is 7 people. This is a reasonable number especially in rural areas. The mean value of sex is 0.78 which indicates that on average the population comprises of more male than female. Moreover, the type of residence has the mean value of 0.23 which is less than 0.5 and it implies that the majority of the poorest are residing in rural areas than in urban areas. The mean value for the variable FSaccess which measures the access to financial services has the mean value of 0.56 and the standard deviation of 0.5. This implies that many households have access to financial services but there is no significant difference between those with access and those without access. The standard deviations show that there is no significant deviation of observations from their mean.

Table 1: Summary Statistics

\begin{tabular}{lrrrrr}
\hline Variable & Obs. & Mean & Std. Dev. & Min & Max \\
\hline Age & 37,169 & 35.90941 & 7.994907 & 15 & 49 \\
Agesq & 37,169 & 1353.403 & 560.6446 & 225 & 2401 \\
Sex & 37,169 & 0.789637 & 0.407572 & 0 & 1 \\
HHsize & 37,169 & 7.289892 & 3.922549 & 1 & 48 \\
Residence & 37,169 & 0.229331 & 0.420408 & 0 & 1 \\
FSaccess & 19,195 & 0.556551 & 0.496805 & 0 & 1 \\
\hline
\end{tabular}

\subsection{Ordered Logit Estimation Results}

Table 2 presents the results for both coefficients, marginal effects and their corresponding standard errors. All variables are statistically significant at $1 \%$ except sex of the head of households (male) which is statistically significant at 5\%. It can be noted from the same table that the sign of the coefficients of the variables and the sign of their corresponding marginal effects are alternating. The marginal effects presented are for the lowest outcome which reflects the probability of being the poorest category. The marginal effect of age $(-0.004)$ shows that the increase in age reduces the probability of being poorest than being in any other category by 0.4 percentage point. This is similar to when the household is headed by a male. However, the study conducted by Baiyegunhi \& Fraser, (2010) shows that households headed by old age people are more vulnerable to poverty than those headed by younger people. The marginal effects for the size of the household is 0.003 which implies that the increase of one member of the household increases the probability of that household being poorest by 0.3 percentage points. This is due to the fact that the higher the size of the household the higher the dependency which causes the poverty persistence.

These findings are consistent with the findings of Makame \& Mzee, (2014) and Ermiyas et al., (2019). However, some studies like Meyer \& Nishimwe-Niyimbanira, (2016) reveal that the relationship between poverty and the household size may also be negative. This is because large households require large income to escape poverty. Furthermore, the marginal effects for education level is $-0.034,-0.091$ and -0.10 for primary level, secondary level and higher level respectively. This implies that the probability of being poorest decreases as the household head is educated by 3.4, 9.1 and 10 percentage points if the household's head has primary education, secondary education and higher education respectively. There is a positive relationship between the level of education and the marginal effects. These results are consistent with Mok et al., (2007) and Apata et al., (2010). Wedgwood, (2015) argues that getting children into school on its own is not enough for poverty reduction because the quality of education is also important to realize potential benefits of education on poverty reduction.

The results further reveal that by living together as partners reduces the probability of being poorest by 12 percentage points than never being in union or living without partners. The type of residence being urban reduces also the probability of being poorest by 10 percentage points than living in rural areas. This is due to the reason that in urban areas there is many economic activities taking place than in rural areas where they mainly depend on agriculture which is seasonal. This results comply with the results of Abuka et al., (2007) who studied determinants of poverty vulnerability in Uganda and found that poverty is more pronounced in rural areas than urban as more remunerative economic activities tend to be concentrated in urban areas.. The marginal effect for 
FSaccess which measures the use of phone to access financial services is -0.020 which can be interpreted as the probability of being poorest decreases by 2 percentage points when the households have access to financial services than when they are not. These findings comply with the findings of Sife, Kiondo, \& Lyimo-Macha, (2010) who found that mobile phones contribute to reduce poverty and improve rural livelihood.

\section{Table 2: Ordered Logit Estimation Results}

\begin{tabular}{|c|c|c|}
\hline Variables & Coefficients & Marginal Effects \\
\hline Age & $\begin{array}{c}0.096 * * * \\
(0.016)\end{array}$ & $\begin{array}{c}-0.004 * * * \\
(0.001)\end{array}$ \\
\hline Agesq & $\begin{array}{c}-0.001 * * * \\
(0.000)\end{array}$ & $\begin{array}{c}0.000 * * * \\
(0.000)\end{array}$ \\
\hline 1.Sex & $\begin{array}{c}0.089 * * \\
(0.042)\end{array}$ & $\begin{array}{c}-0.004 * * \\
(0002)\end{array}$ \\
\hline HHsize & $\begin{array}{c}-0.069 * * * \\
(0.004)\end{array}$ & $\begin{array}{c}0.003 * * * \\
(0.000)\end{array}$ \\
\hline 1.Education & $\begin{array}{c}0.451 * * * \\
(0.038)\end{array}$ & $\begin{array}{c}-0.034 * * * \\
(0.003)\end{array}$ \\
\hline 2.Education & $\begin{array}{c}2.483 * * * \\
(0.053)\end{array}$ & $\begin{array}{c}-0.091 * * * \\
(0.003)\end{array}$ \\
\hline 3.Education & $\begin{array}{c}4.760 * * * \\
(0.441)\end{array}$ & $\begin{array}{c}-0.10 * * * \\
(0.004)\end{array}$ \\
\hline 1.Marstat & $\begin{array}{c}0.246 * * * \\
(0.086)\end{array}$ & $\begin{array}{c}-0.12 * * * \\
(0.005)\end{array}$ \\
\hline 2.Marstat & $\begin{array}{l}-0.020 \\
(0.087)\end{array}$ & $\begin{array}{c}0.001 \\
(0.005)\end{array}$ \\
\hline 1.Residence & $\begin{array}{c}2.555 * * * \\
(0.038)\end{array}$ & $\begin{array}{c}-0.10 * * * \\
(0.002)\end{array}$ \\
\hline 1.FSaccess & $\begin{array}{c}0.391 * * * \\
(0.029)\end{array}$ & $\begin{array}{c}-0.020 * * * \\
(0.001)\end{array}$ \\
\hline Constant cut 1 & $\begin{array}{c}0.563 * * \\
(0.278)\end{array}$ & \\
\hline Constant cut2 & $\begin{array}{c}1.725 * * * \\
(0.278)\end{array}$ & \\
\hline Constant cut3 & $\begin{array}{c}2.995 * * * \\
(0.279)\end{array}$ & \\
\hline Constant cut4 & $\begin{array}{c}4.975 * * * \\
(0.280)\end{array}$ & \\
\hline Observations & 19,195 & 19,195 \\
\hline
\end{tabular}

Robust standard errors in parentheses

$* * * \mathrm{p}<0.01, * * \mathrm{p}<0.05, * \mathrm{p}<0.1$

\subsection{Conclusion and Policy Implication}

The current study reveals that the main determinants of poverty are the age, sex, education, marital status of the head of household. Also the type of residence of the household and access to financial services play important role in explaining the status of poverty of households. The study recommends that the government should invest more in education since the economy with educated labor force performs better and this ensures achieving the fourth sustainable development goal which requires the government to provide quality and inclusive education for upward social mobility and poverty reduction. Since access to financial services is significant in reducing poverty, the government should ensure improved financial services and financial inclusion especially in rural areas to eradicate poverty. On the other hand, the rural-urban disparity need to be removed to ensure equality in poverty reduction in both rural and urban areas through measures like equality in allocation of resources in both rural and urban areas.

\section{References}

Abuka, C. A., Atingi-Ego, M., Opolot, J., \& Okello, P. (2007). Determinants of poverty vulnerability in Uganda. Adeyemi, S. L., Ijaiya, G. T., \& Raheem, U. A. (2009). Determinants of Poverty in Sub-Saharan Africa. African Research Review, 3(2), 162-177. 
Aikaeli, J. (2010). Determinants of Rural Income in Tanzania: An Empirical Approach. Dar es Salaam.

Al-samarrai, S. (2007). Changes in employment in Bangladesh, 2000-2005: The impacts on poverty and gender equity.

Apata, T. G., Apata, O. M., Igbalajobi, O. A., \& Awoniyi, S. M. O. (2010). Determinants of rural poverty in Nigeria: Evidence from small holder farmers in South-western, Nigeria. Journal of Science and Technology Education Research, 1(4), 85-91.

Arif, M. Z. U. (2014). Women Empowerment and Poverty Reduction through Participation of Women in Microfinance with Reference to Bangladesh. International Journal of Management, 3(5), 41-52. https://doi.org/10.15410/aijm/2014/v3i5/53727

Baiyegunhi, L., \& Fraser, G. (2010). Determinants of Household Poverty Dynamincs in Rural Regions of the Eastern Cape Province, South Africa. Poster Presented at the Joint 3rd African Association of Agricultural Economists (AAAE) and 48th Agricultural Economists Association of South Africa (AEASA) Conference, Cape Town, South Africa, September 19-23, 2010.

Becker, G. S. (1962). Investment in Human Capital:A theoretical Analysis. The Journal of Political Economy, LXX(5), 9-49. Retrieved from http://www.nber.org/books/univ62-3

B. Korf, A. Bogale, and K. Hagedorn,(2005) Determinants of poverty in Rural Ethiopia, Quarterly Journal of International Agriculture 44, 2005, No 2, 101-120

Bundervoet, T. (2006). Estimating Poverty in Burundi (No. 20).

Castañeda, A., Newhouse, D., Doan, D., Nguyen, M. C., Uematsu, H., \& Azevedo, J. P. (2016). Who Are the Poor in the Developing World?

Chikelu, J. C. (2016). Impact of Human Capital Development on Poverty Reduction in Nigeria Impact of Human Capital Development on Poverty Reduction in Nigeria. MPRA, (74696). Retrieved from https://mpra.ub.uni-muenchen.de/74696/

Coulombe, H., \& Mckay, A. (1996). Modeling determinants of poverty in Mauritania. World Development, 24(6), $1015-1031$.

DFID. (2005). Reducing poverty by tackling social exclusion: A DFID policy Paper. UK.

Ermiyas, A., Batu, M., \& Teka, E. (2019). Determinants of Rural Poverty in Ethiopia: A Household Level Analysis in the Case of Dejen Woreda. Arts and Social Sciences Journal, 10(2). https://doi.org/10.4172/2151-6200.1000436

Gachanja, P. M., \& Kinyanjui, G. K. (2016). Household Poverty Determinants in Kenya : A Demographic and Health Survey Wealth Index Approach by. Africology: The Journal of Pan African Studies, 9(3), 52-65.

Horrell, S., \& Krishnan, P. (2006). Poverty and Productivity in Female-Headed Households in Zimbabwe Poverty and Productivity in Female-Headed Households in Zimbabwe Sara Horrell and Pramila Krishnan. Journal Development Studies, 43(8). https://doi.org/10.1080/00220380701611477

Long, J. S. (1997). Regression Models for Categorical and Limited Dependent Variables. Thousand Oaks, California: SAGE Publications, Inc.

Majeed, M. T., \& Malik, M. N. (2014). Determinants of Household Poverty: Empirical Evidence from Pakistan, (57744), 1-16. Retrieved from http://mpra.ub.uni-muenchen.de/57744/ MPRA Paper No. 57744, posted 5. August 2014 09:16 UTC

Makame, I. H., \& Mzee, S. S. (2014). Determinants of Poverty on Household Characteristics in Zanzibar: A logistic Regression Model. Developing Country Studies, 4(20), 188-196.

Meyer, D. F., \& Nishimwe-Niyimbanira, R. (2016). The impact of household size on poverty: An analysis of various low-income townships in the Northern Free State region, South Africa. African Population Studies, 30(2r). https://doi.org/10.11564/30-2-811

Mok, T. Y., Gan, C., \& Sanyal, A. (2007). The Determinants of Urban Household Poverty in Malaysia. Journal of Social Sciences, 3(4), 190-196.

Mutabazi, K. D., Sieber, S., Maeda, C., \& Tscherning, K. (2015). Assessing the determinants of poverty and vulnerability of smallholder farmers in a changing climate: the case of Morogoro region, Tanzania. Reg Environ Change. https://doi.org/10.1007/s10113-015-0772-7

Narayan, D. (2000). Poverty Is Powerlessness and Voicelessness, 37(4).

Narayan, D; Patel, R; Schafft, K; Rademacher, A and Koch-Schulte S. (2000a) Voices of the Poor: Can Anyone Hear Us? New York: Oxford University Press.

Nor Amira Mohamad, Zalila Ali, Norlida Mohd Noor, and A. B. (2016). Multinomial logistic regression modelling of stress level among secondary school teachers in Kubang Pasu District, Kedah Multinomial Logistic Regression Modelling of Stress Level Among Secondary School Teachers in Kubang Pasu, 060018. https://doi.org/10.1063/1.4954623

F. I. Kabuya,(2007) Economics for African nations, principles, problems and policies, Victoria, Canada Okojie, C. E. E. (2002). Gender and Education as Determinants of Household Poverty in Nigeria (No. 37).

Schultz, T. W. (1961). Investment in Human Capital.pdf. The American Economic Review, 51(1), 1-17. 
Sengupta, A. (2003). Poverty eradication and human rights. New York.

Shaukat, B., Javed, S. A., \& Imran, W. (2019). Wealth Index as Substitute to Income and Consumption: Assessment of Household Poverty Determinants Using Demographic and Health Survey Data. Journal of Poverty, 1-21. https://doi.org/10.1080/10875549.2019.1678550

Sife, A. S., Kiondo, E., \& Lyimo-Macha, J. G. (2010). Contribution of Mobile Phones to Rural Livelihoods and Poverty Reduction in Morogoro, Tanzania. Electronic Journal of Information Systems in Developing Countries, 42(3), 1-15. https://doi.org/10.1002/j.1681-4835.2010.tb00299.x

Tilak, J. (2002). Education and Poverty. Journal of Human Development and Capabilities, 3, 191-207. https://doi.org/10.1080/14649880220147301

Todaro, M. P., \& Smith, S. C. (2015). Economic Development Twelfth Edition (12th ed.). New Jersey,USA: Pearson.

URT. (2018). Tanzania Human Development Report 2017: Social Policy in the Context of Economic Transformation. Dar es Salaam.

Wedgwood, R. (2015). Education and poverty reduction in Tanzania. International Journal of Educational Development, 27(2007), 383-396. https://doi.org/10.1016/j.ijedudev.2006.10.005

World Bank. (2018). Poverty and Shared Prosperity 2018: Piecing Together the Poverty Puzzle. Washington, DC.

Yusuf, H. M., Daninga, P. D., Xiaoyun, L., Studies, D., District, H., Mwalimu, T., ... Division, E. (2015). Determinants of Rural Poverty in Tanzania: Evidence from Mkinga District, Tanga Region. Developing Country Studies, 5(6), 40-49.

Zuluaga, B. (2002). Different Channels of Impact of Education on Poverty: An Analysis for Colombia, 1-23. Retrieved from www.econ.kuleuven.be/CES/discussionpapers/Dps07/Dps0702.pdf

Zuluaga, B. (2010). Different Channels of Impact of Education on Poverty : An Analysis for Colombia. SSRN Electronic Journal, 26(114), 13-37. https://doi.org/10.2139/ssrn.958684 